continues all night. One frequently finds it impossible to sleep there though in the very best of health, and this is directly attributed to the electric discharge, this fact is noted by Mr. Stone.

To my mind the most important line of investigation is that regarding the connection between this discharge and the agglomeration of vapor molecules into cloud particles. Experiments have already shown a most marked effect upon steam when an electric discharge is passed into it. On Mt. Washington there are dense clouds weeks at a time, while a mile or two from the summit the sky may be perfectly clear. A most careful study of the phenomenon has shown that it could not be due to the rocks of the summit being cooler than the air, as thought by many, for the rocks were always warmer than the air except on nights when there were no clouds. Nor could the persistent cloud be due to the expansion and consequent cooling of air rushing up the side of the mountain for the peak is a sharp cone at the last 500 feet and the cloud-hood extended on all sides to a mile or two. It would seem probable that a careful study with instruments of the phenomena of mountain electric discharges would shed a great deal of light on the exceedingly complex subject of clouds and rain-formation about which we know nothing except that the ordinary theories need thorough revision. H. A. HAZEN.

Washington, D.C., Dec. 10.

\section{A Multiple Key.-Preliminary Note.}

IN psychological laboratories it is frequently desirable to make or break two or more electrical currents at the same instant.

Ewald's key solves this problem for the most simple cases, but a need for something more elaborate was felt. This led to the invention by Dr. Scripture and the construction in the work-shop of the Yale Psychological Laboratory of a multiple key which meets all present requirements. Ewald's key costs 20 marks; this one, made by the laboratory mechanic, of unlacquered brass, without platinum contacts, was made at a cost of less than $\$ 10$.

It is arranged so that five currents can run through it. One, two, or three of these can be made and one broken at the same time. The other can either be made or broken at the same time or broken for an instant and then made again; or these makes and breaks can be adjusted so as to occur one after the other in any order. By reversing the key, it gives three breaks and two makes.

An illustration of the use of the key can be taken from one of the problems in reaction time now being investigated. A single movement of the key first breaks the shunt of the tuning-fork circuit and starts the time-marker vibrating on the recording drum; an instant later, say, .03 of a second, it closes a telephone circuit running to the reacting-room from the sound-room, thus producing the stimulus; it simultaneously breaks a current running through the registering signal on the drum and a closed key in the reaction room. This current is automatically closed again within .02 of a second, and again broken by the reaction on the closed key. As soon as the reaction takes place, the key is released and the tuning-fork curve stopped before the drum has made a complete revolution, thus saving all motion of the marker during the experiment, as well as space on the smoked paper. This not only saves much time, but also renders the records more legible and consequently more accurate.

New Haven, Conn., Dec. 19.

Charles B. Bliss.

\section{Excitement Over Glacial Theories.}

Probably I have as much reason to be thankful for the frankness of Mr. McGee's letter in Science for Dec. 2, as for the courtesy of Dr. Brinton's previous review of my volume on "Man and the Glacial Period," for it doubtless gives expression to sentiments held by many persons in private, and it is better that $I$ should have occasion to explain the misapprehensions which evidently prevail in some quarters. I beg, therefore, the privilege of your space for a brief statement of some points.

Mr. McGee refers to an apparent discrepancy between my observations on the rate of movement of the Muir Glacier and those of Professor Reid. If he had read Professor Reid's article care fully he would have seen that the discrepancy is more apparent than real. Professor Reid distinctly states that there was a quarter of a mile or more of width in the glacier which he was unable to reach with his stakes, and whose motion he therefore failed to measure, whereas by our method of taking angles directly upon the ice-pinnacles we were able to measure the portions which were presumably moving most rapidly.

As to my connection with the U. S. Geological Survey, the facts are that after I bad, on the Pennsylvania Survey and at much private expense, mapped the glacial boundary from the Delaware River to Illinois, and published the results with considerable fulness, I was asked, in 1884 , to complete the work to the Mississippi River for the U. S. Geological Survey and prepare a report on the whole line from there to the Allegheny Mountains. This I did, and the report was duly published in 1890. My formal connection with the Survey did not terminate until a month after the publication of my last book. I am not aware that any substantial error has been pointed out in my delineation of the southern border of the ice-sheet, which I was set to accomplish (see The Dial for Dec. 16, 1892).

The real point at issue relates to the question of the unity, or one might better say the "continuity" of the glacial period, and the disturbance all arises over the fact that I have been led to interpret the facts in accordance with the theory of glacial continuity, while Mr. McGee and some of his associates are committed to the theory that there were two or more distinct epochs. It is sufficient for me here to say that my conclusions are based on a large amount of field-work, and are supported by a respectable number of able geologists, and have recently been set forth at considerable length in an article in the November number of the American Journal of Science. In this I have not wholly disregarded Mr. McGee's science of geomorphy though $\mathrm{I}$ have not called it by that name.

Perhaps the best way for me to answer the charge of general ignorance will be to state in a few words the conception of the progress of events during the glacial period which $I$ have been slowly led to entertain.

During the most of the Tertiary period the lands were low towards the pole and a warm climate prevailed. Toward the close of the Tertiary a slow elevation of these northern lands was in progress until they stood, say, 3,000 feet higher than now. This is shown by the fiords which characterize both sides of the continent from the latitude of Chesapeake Bay northward.

This elevation of land was probably the predominant cause of the glacial period, for the ice-movement in North America radiated, not from the pole, but from Labrador and the region about Hudson Bay. This elevation was accompanied by a rapid deepening of the river channels over the area and the consequent accumulation of detritus about their mouths.

Ice finally accumulated nearly a mile deep over the area north of the linemarking the "drift" and extending to New York City and Cincinnati. This accumulation of ice was coincident with, if not the cause of, a depression of the land in the more northern portions several hundred feet below its present level.

The final melting of the ice proceeded with great rapidity, but with various halts and oscillations of the front. The period of oscillation of the glaciers in the Alps is something like half a century. The periods during the great ice age were probably much longer, but a few centuries seems ample to account for the longest. These oscillations are marked by what Professor Cook aptly called "moraines of retrecession," of which there are twelve in Ohio.

Applying the principles of Mr. McGee's science of geomorphy, I explain the phen rmena of slackened drainage which characterize the deposits along the extreme margin of the glaciated area as connected with the subsidence of the land increasing to the north, which marked the climax of the period, while the more vigorous signs of drainage action farther north are the natural results of the northerly re-elevation wbich went on synchronously with the unloading of the weight of the ice by melting. It is in these later stages of the deposition of ground that we find the remains of palæolithic man.

Whether this theory of the progress of events is correct or not. 
it is based on wide observations of facts and long reflection on the elements of the problem, in which I have had the assistance and support of many able geologists, and they are views which cannot wisely be dismissed without careful consideration of the arguments upon which they rest. The theory is not without its difficulties; neither is any other. Geology is not an exact science. There is no infallible court of appeal for the settlement of theo ries. Observers and students of the facts may widely differ for a long time in their conclusions without discredit to either party. I can only ask for freedom of opinion and freedom of utterance.

oberlin, 0 .

G. FREDERICK WRIGHT.

Notice of the Occurrence of Nyctale Richardsoni, Richardson's Owl, in Nebraska.

THE occurrence in this region of Richardson's owl, Nyctale Richardsoni, seems to be entirely established by the recent capture of one in Lincoln. This is a long distance below its soutbern limit, and its appearance is something of a surprise.

However, Professor Lawrence Bruner, who has stuffed and mounted this rare owl, noticed one as a boy, twenty four years ago, near Omaha. Ornithologists at the time questioned the accuracy of his observations, but this specimen confirms the probability of his claim.

The present specimen, which is the first actually taken in the State, was captured on 33d Street, in the city of Lincoln, Dec. 12, and was brought alive to the State Museum. It lived but a short time, however, owing perhaps to injuries, or to the heat. The bird is an adult, in fine plumage.

The unexpected appearance of this inhabitant of Arctic regions seems the more striking from the fact that the weather in Nebraska thus far, barring one snow-storm, has been a mild, protracted autumn rather than winter.

University of Nebraska, Lincoln, Neb., Dec. 14.

\section{Vagueness of Localization in a Child.}

The following are illustrations of the vagueness of the localization of cutaneous sensations in children. The one referred to is 16 months old. The morning after she had been vaccinated, and for a considerable time afterward, she was unable to tell on which arm the sensitive spot was situated, often looking at or touching the wrong one. On one occasion the child sat down with her back close to a grate-fire; as soon as the heat had penetrated the clothing, she began pulling at and striking her chest as though the sensation were there. M. SCRIPTURE.

New Haven, Conn.

\section{Ballistic Galvanometer.}

CAN any of your readers furnish me with complete references on the use of the ballistic galvanometer for measurements of time? E. W. SCRIPTURE.

Yale University, New Haven, Conn.

\section{BOOK-REVIEWS,}

The California Vine Disease. By Newton B. Pierce Bulletin No. 2. Division of Vegetable Pathology, U. S. Dep't. Agric. Washington, 1892. $222 \mathrm{p}, \mathrm{pl}$. 25, charts 2.

Report on the Experiments made in 1891 in the Treatment of Plant Diseases. By B. T. Galloway. Bulletin No. 3. Division of Vegetable Pathology, U. S. Dep't. Agric. Washington, $1892 . \quad 76 \mathrm{p}, \mathrm{pl} .8$.

Grasses of the Pacific Slope, including Alaska and the Adjacent Islands. By Geo. VAseY. Bulletin No. 13. Division of Botany. U. S. Dep't. Agric. Washington, 1892. 50 plates, with descriptions.

THESE three publications which have followed one another rapidly from the Government printing office are of diverse character. The first deals with the results of an investigation extending over two years into the character of an obscure but virulent disease of vines in California; the second records the results of a series of experiments to prevent the ravages of several plantdiseases in the eastern portion of the country; and the third gives descriptions and plates of fifty-two species of grasses found growing on the Pacific coast of our country, including Alaska.

The California vine disease seems to have first appeared in the vicinity of Anaheim, Orange County, in 1885, but it did not attract great attention until the following year, when it caused the death of a large number of vines. From this, its first appearance, it has spread over a wide section of the surrounding country and has caused the death of many thousands of vines and entailed a loss of many thousands of dollars. Mr. Pierce, as the special agent of the Department of Agriculture, had spent two years in studying the subject when the present report was sub. mitted, in June, 1891, and since then has continued his investigations. The report is an exhaustive one in many respects, an unsatisfactory one in others. For example, while he has given a very full account of the rise and progress of the vine industry in California and Mexico, and has examined with great care the bearings of soil conditions and of meteorological phenomena on the disease, the remedy for the evil, or even suggestions for palliation of it, are meagre in the extreme. It might be said, it is true, that as the origin and cause of the disease is still unknown, it is not possible to prescribe a remedy. Everything that has so far been tried bas given negative results. Numerous facts have been brought out by the investigation. Among them may be noted that drainage, irrigation, soil characters, rainfall, and temperature have had no effect in causing the disease. But that shade has in some unknown manner the effect of retarding the progress of the malady. It has also been ascertained that the disease is not caused by certain species of fungi or by certain animal or insect parasites, and that it differs in several ways quite markedly from Chlorosis and Pouritiore as these occur in Europe. The colored plates that are given illustrate very well the effects of the disease on the leaves and canes.

The second of the titles above given is an account of experiments conducted in the vicinity of Washington and in New York State for the prevention of plant diseases. These experiments bear out the previous work of the department. They show that, in the treatment of black rot of the grape, Bordeaux mixture still takes the lead; and that half strength, i. e, 3 pounds of copper sulphate, 2 pounds of fresh lime, and 22 gallons of water, gives as good practical results as full strength. In the treatment of apple scab, Bordeaux mixture was also very effective, but not so much so as Paris green. This is a new fact inasmuch as this substance, while known to be effective against insects, has not been generally supposed to be a fungicide. There was a higher percentage of first quality fruits and a less percentage of third quality as well as wormy fruits when this substance was used than any other. The experiments in New York were largely negative, since the amount of disease present was comparatively slight. The subjects treated were various kinds of nursery stock, and here again Bordeaux mixture gave as a whole the best results. Two plates showing sprayed and unsprayed grapes bear testimony to the good effects of the treatment for black rot.

The third title, "Grasses of the Pacific Slope," consists of illustrations and descriptions of grasses growing in California. Oregon, Washington, and Alaska. Some of them are of value for forage, while others are of scientific interest only. This is Part I. of the second volume of "Iilustrations of North American Grasses," the first volume, also in two parts, haring treated of the grasses of the south-west. The reports cannot fail to be of great interest and value to all students of botany.

JOSEPH F. JAMES.

Comparative Architecture. By BARRE FerReE. The author, New York.

THIS is a reprint of a paper read before the American Institute of Architects at its twenty-fifth annual meeting, at Boston, in October, 1891. Il is handsomely printed in royal octavo, and covers fifteen pages in clear and pleasing type. In this discourse, the distinguished author applies to architecture the comparative method which has proved so fruitful in the study of language and of biology. "Comparative Architecture" takes " the facts of historical and descriptive architecture, and describes the comparative progress made by all nations, and under all conditions." 